\title{
Blood cardioplegia in the senescent heart
}

As an increasingly aged population undergoes cardiac surgery, myocardial protective strategies must address the fundamental differences between adult and senescent myocardium. In a test of the hypothesis that senescent myocardium is less tolerant of cardioplegic arrest, adult (0.5 to 1.0 years) and senescent ( 6 to 9 years) sheep underwent 55 minutes of hypothermic blood cardioplegic arrest. A 5-minute dose of terminal warm blood cardioplegic solution was administered followed by 30 minutes of vented reperfusion. Left ventricular volume was monitored by means of sonomicrometric crystals in three orthogonal planes. Myocardial function was assessed with the preload recruitable stroke work relationship. Diastolic function was assessed with two techniques: the "stiffness" coefficient $(\beta)$, derived from the exponential end-diastolic pressure-volume relationship, and the time constant of isovolumic left ventricular pressure decay (tau). Data were acquired before arrest and after the reperfusion period. Contractility in the adult hearts was well preserved (preload recruitable stroke work: $63.7 \pm 6.1$ versus $56.8 \pm 4.1 \mathrm{~mJ} /$ beat per milliliter per $100 \mathrm{gm}$, prearrest versus postarrest, $p=$ not significant). In contrast, senescent heart contractility was poorly preserved $(56.8 \pm 4.1$ versus $35.4 \pm 4.2 \mathrm{~mJ} /$ beat per milliliter per $100 \mathrm{gm}, p<0.025)$. Early diastolic relaxation (tau) was prolonged in the adult hearts $(42.5 \pm 3.3$ versus $48.8 \pm 3.5 \mathrm{msec}$ prearrest versus postarrest, $p<0.05$ ), whereas the senescent hearts were essentially unchanged $(49.3 \pm 3.1$ versus $52.3 \pm 4.5 \mathrm{msec}, p=0.35$ ). Myocardial stiffness $(\beta)$ was unchanged in both groups. When compared with adult hearts, contractility in senescent hearts is poorly preserved after cold blood cardioplegic arrest. Active diastolic relaxation, however, is more prolonged in adult hearts. Passive diastolic properties are unchanged in both groups. Because there are specific age-related differences in tolerance to cardioplegic arrest, extrapolation of myocardial protective strategies from studies in adult hearts to elderly patients may not be appropriate. (J THORAC CARDIOvasC SURG 1995;109: 269-74)

Christopher A. Caldarone, MD, Irvin B. Krukenkamp, MD, Paul G. Burns, MD, Glenn R. Gaudette, MSc, Joshua Schulman, and Sidney Levitsky, MD, Boston, Mass.

\footnotetext{
A dvances in myocardial preservation and perioperative support have allowed cardiac surgery in an increasingly aged population. ${ }^{1,2}$ The foundation on which these advances have been made involves

From the Division of Cardiothoracic Surgery, New England Deaconess Hospital, Harvard Medical School, Boston, Mass.

Presented in part at the American College of Surgeons Clinical Congress, San Francisco Calif., Oct. 12, 1993.

Supported by National Institutes of Health grants HL29077 (S.L.) and HL48751 (I.B.K.)

Received for publication Jan. 28, 1994.

Accepted for publication July 12, 1994.

Address for reprints: Irvin B. Krukenkamp, MD, 110 Francis St, Suite 2-C, Boston, MA 02215.

Copyright (ㅇ) 1995 by Mosby-Year Book, Inc.

$0022-5223 / 95 \$ 3.00+0 \quad \mathbf{1 2 / 1 / 5 9 1 5 8}$
}

investigation with adult experimental animals and human subjects and, consequently, extrapolation of these results to the senescent heart. The validity of this extrapolation, however, has gone largely untested. Studies of the senescent heart have defined specific age-related alterations in multiple biochemical and morphologic parameters, including adrenergic responsiveness, ${ }^{3}$ calcium transport, ${ }^{4,5}$ excitation-contraction coupling, ${ }^{6}$ and myocyte cell loss/ hyperplasia. ${ }^{7}$ The results suggest that senescent hearts may have a different response to cardioplegic arrest than adult hearts. Furthermore, investigations in this laboratory, with the use of in vivo large animal preparations, have demonstrated that senescent hearts are more vulnerable to global ischemia than adult hearts. ${ }^{8}$ To date, however, no study has 
Table I. Composition of cardioplegic solution

\begin{tabular}{lcc}
\hline & Cold & Warm \\
\hline Temperature $\left({ }^{\circ} \mathrm{C}\right)$ & 10 & 37 \\
Potassium $(\mathrm{mEq} / \mathrm{L})$ & 7 & 14 \\
Magnesium $(\mathrm{mmol} / \mathrm{L})$ & 7 & 7 \\
Dextrose $(\mathrm{mmol} / \mathrm{L})$ & 54.4 & 54.4 \\
$\mathrm{pH}$ & 7.65 & 7.652 \\
\hline
\end{tabular}

directly compared tolerance of the adult and senescent myocardium to cardioplegic arrest.

The present study was therefore undertaken with the use of a commonly employed cardioplegic technique (cold blood cardioplegia with a terminal interval of warm blood cardioplegia ${ }^{9,10}$ ) in adult and senescent sheep. The objective of the study was to ascertain whether previously reported differences in adult and senescent myocardium translate into an alteration in the myocardial tolerance to cardioplegic arrest in the early postoperative period.

\section{Methods and materials}

All animals received humane care in compliance with the "Principles of Laboratory Animal Care" formulated by the National Academy of Sciences and the "Guide for the Care and Use of Laboratory Animals" prepared by the Institute of Laboratory Animal Resources and published by the National Institutes of Health (NIH Publication No. 86-23, revised 1985).

Preparation. Eight adult (aged 0.5 to 1 year) and seven senescent (aged 6 to 9 years) Dorsett or Suffolk sheep were sedated (ketamine $20 \mathrm{mg} / \mathrm{kg}$ ) and anesthetized with pentobarbital $25 \mathrm{mg} / \mathrm{kg}$ ). The criteria used to define adulthood was the age at which the sheep were considered to be sexually mature. ${ }^{8}$ After tracheostomy and initiation of volume-cycled ventilation, pancuronium $(50 \mu \mathrm{g} / \mathrm{kg})$ was administered and sternectomy with bilateral rib resection performed. The carotid artery and internal jugular vein were cannulated for central venous pressure monitoring and venous access, respectively. The right azygos and left hemiazygos veins were ligated. A pericardial cradle was formed and $5 \mathrm{mHz}$ ultrasonic dimension crystals were sutured to the epicardium in three orthogonal pairs. After systemic anticoagulation (heparin 250 units $/ \mathrm{kg}$ ), total cardiopulmonary bypass was initiated at a flow rate of 75 $\mathrm{ml} / \mathrm{kg}$ per minute. A left ventricular (LV) micromanometer was inserted through the apex for intracavitary pressure monitoring and a large-bore cannula was used to decompress the right ventricle through the pulmonary artery.

Protocol. All studies underwent initial data acquisitions during incremental volume loading on modified right heart bypass as has been described..$^{10}$ In brief, inflow from the cardiopulmonary bypass machine to the LV was increased from 75 to $150 \mathrm{ml} / \mathrm{kg}$ per minute in increments of 10 to $15 \mathrm{ml} / \mathrm{kg}$ per minute (six to eight steps). At each increment, the ventricle was allowed to equilibrate for 1 to 2 minutes, after which pressure-volume data were re- corded every $2 \mathrm{msec}$ for a 15 -second interval. LV epicardial volume was calculated with the use of the ultrasonic dimension crystal data in three dimensions with an ellipsoid model. Pressure-volume loops were then constructed, representing the external work per beat expressed in millijoules per beat per $100 \mathrm{gm} \mathrm{LV}$ weight.

Contractility was assessed with the preload recruitable stroke work relationship (PRSW) as described by Glower and associates, ${ }^{12}$ which uses the slope of the relationship between preload (end-diastolic volume) and external work as an estimate of contractility. Diastolic function was assessed by two methods. Active relaxation was estimated according to the method of Weiss, Frederiksen, and Weisfeldt ${ }^{13}$ by fitting the LV pressure decay waveform during isovolumic relaxation to the following equation:

$$
P(t)=a \cdot e^{(-t / T)}
$$

where $\mathrm{a}$ is a constant, $\mathrm{t}$ is time during the interval from peak negative rate of pressure rise to the point at which the pressure decays to $5 \mathrm{~mm} \mathrm{Hg}$ above the end-diastolic pressure of the preceding beat, and $T$ is tau, the time constant of isovolumic pressure decay. The passive properties of the myocardium were described by fitting an exponential equation

$$
\operatorname{EDP}=\alpha \cdot \mathrm{e}^{(\beta \cdot \operatorname{EDV})}
$$

to the end-diastolic pressure (EDP)-end-diastolic volume (EDV) relationship, where $\alpha$ and $\beta$ are constants and $\beta$ represents the diastolic stiffness coefficient.

Hyperkalemic cold blood cardioplegic solution $(20 \mathrm{ml} /$ $\mathrm{kg}$ ) was then administered antegradely through the aortic root, producing prompt diastolic arrest (Table I). Topical hypothermia was applied and the posterior LV intramyocardial temperature was maintained at approximately $10^{\circ} \mathrm{C}$. Cardioplegic solution was readministered every 20 minutes $(10 \mathrm{ml} / \mathrm{kg})$. Infusion pressures were monitored at the aortic root and maintained at 80 to $100 \mathrm{~mm} \mathrm{Hg}$. After 55 minutes, a 5-minute dose of warm cardioplegic solution was administered. ${ }^{8}$ The cross-clamp was removed and the hearts were allowed to resume beating for 30 minutes of vented reperfusion. After the reperfusion period, a second incremental volume loading was initiated to obtain data on postarrest mechanics. All hearts were then excised, confirmed to be free of gross atherosclerotic disease, trimmed, and the LVs weighed. During the arrest period, myocardial oxygen consumption was also calculated during each administration of cardioplegic solution.

Data are presented as mean \pm standard error of the mean, with a $p$ value $<0.05$ considered to indicate a significant difference between groups. Summary data were compared within groups by a paired $t$ test and between groups by one-way analysis of variance.

\section{Results}

Group characteristics are summarized in Table II. The body weight and LV weight of the senescent sheep were greater than those of the adults. When normalized to body weight, however, the adult hearts tended to be larger than the senescent hearts (3.2 \pm 0.1 versus $2.8 \pm 0.1$ gm LV per kilogram body 
weight, $p=0.057)$. On the first step in incremental volume loading, LV inflow was set at $75 \mathrm{ml} / \mathrm{kg}$ per minute. Hemodynamic parameters are also summarized in Table II. Heart rate and systolic blood pressure were similar in the two groups. Although the end-diastolic volume was smaller in the adult hearts ( $96 \pm 8$ versus $141 \pm 12 \mathrm{ml}, p<0.005)$, when normalized to total body weight or to LV weight, the groups were nearly identical. Therefore, there is little evidence of gross myocardial hypertrophy or severe hypertensive disease as possible confounding factors in this study.

Contractility data are summarized in Table III. Contractility assessed with the slope of the PRSW relationship was decreased by $9 \%$ in the adult hearts $(63.7 \pm 6.1$ to $56.8 \pm 4.1 \mathrm{~mJ} /$ beat per milliliter per $\left.100 \mathrm{gm}, p=\mathrm{NS}^{*}\right)$. This small decrement in contractility is consistent with a successful myocardial protective strategy. In contrast, postarrest contractility in the senescent hearts was decreased by approximately $38 \%$ (56.8 \pm 3.5 to $35.4 \pm 4.2 \mathrm{~mJ} /$ beat per milliliter per $100 \mathrm{gm})$ when compared with either prearrest values $(p<0.025)$ or adult postreperfusion values $(p<0.025)$. No statistical difference was detected in the prearrest PRSW values.

Diastolic parameters are summarized in Table IV. Dysfunctional active diastolic relaxation estimated with tau was apparent in the adult hearts $(42.5 \pm 3.3$ versus $49.3 \pm 3.1 \mathrm{msec}$, prearrest versus postreperfusion, $p<0.05$ ). The senescent hearts, in contrast, demonstrated only a slight, nonstatistically significant trend toward active diastolic dysfunction $(48.8 \pm 3.5$ versus $52.3 \pm 4.5 \mathrm{msec}, p=0.35)$.

Passive myocardial properties estimated with the ventricular "stiffness" $(\beta)$ constant were unchanged in the adult hearts $(0.028 \pm 0.003$ versus $0.028 \pm$ 0.002 , prearrest versus postreperfusion). The lack of change in the $\beta$ coefficient indicates that the cardioplegia regimen was adequate for the adult hearts. ${ }^{14}$ A statistical difference in the senescent group $\beta$ coefficients was not detected.

During cardioplegic arrest, oxygen consumption calculated at each administration of cardioplegic solution was not statistically different between groups $(0.42 \pm 0.13$ versus $0.59 \pm 0.05 \mathrm{ml}$ oxygen per minute per $100 \mathrm{gm}$, adult versus senescent, $p=\mathrm{NS}$ ).

\section{Discussion}

According to the parameters available to the surgeon in the operating room (hypothermia, dia-

${ }^{*} \mathrm{NS}=$ Not significant
Table II. Group characteristics and hemodynamic parameters during $L V$ volume loading at $75 \mathrm{ml} / \mathrm{kg}$ per minute

\begin{tabular}{lcc}
\hline & Adult & Senescent \\
\hline Age (yr) & $0.5-1.0$ & $6.0-9.0$ \\
Body weight (kg) & $37.9 \pm 0.8$ & $57.6 \pm 2.8^{*}$ \\
LV weight (gm) & $121.6 \pm 4.5$ & $162.9 \pm 6.8^{*}$ \\
LV/body weight (gm/kg) & $3.2 \pm 0.1$ & $2.8 \pm 0.1 \dagger$ \\
Heart rate (beats/min) & $128 \pm 8$ & $117 \pm 5$ \\
SBP (mm Hg) & $85 \pm 6$ & $90 \pm 7$ \\
EDV (ml) & $96 \pm 8$ & $141 \pm 12^{*}$ \\
EDV/body weight $(\mathrm{ml} / \mathrm{kg})$ & $2.5 \pm 0.2$ & $2.4 \pm 0.2$ \\
EDV/LV weight $(\mathrm{ml} / \mathrm{gm})$ & $0.80 \pm 0.42$ & $0.87 \pm 0.7$
\end{tabular}

Data are mean \pm standard error of the mean. $S B P$, Systolic blood pressure; $E D V$, end-diastolic volume.

${ }^{*} p<0.05$ versus adult.

$\dagger p<0.057$ versus adult.

stolic arrest, and delivery of oxygenated cardioplegic solution), both groups of hearts should have been adequately preserved. Because the cardioplegia regimen used in this study is based on adult-derived laboratory data, it is not surprising that the adult hearts had systolic myocardial preservation consistent with previous reports. The lack of adequate myocardial preservation in the senescent hearts, however, illustrates that extrapolation of this particular cardioplegia regimen to the senescent heart may be inappropriate. Inadequate myocardial preservation may be due to maldistribution of cardioplegic solution or an inherent difference in the senescent myocyte response to hypothermic ischemia and reperfusion injury.

Although the adult heart LVs were smaller than the senescent heart LVs $(122 \pm 4.5$ versus $163 \pm 6.8$ gm, $p<0.001$ ), the LV weight/body weight ratio tended to be greater in the adult hearts $(3.2 \pm 0.1$ versus $2.8 \pm 0.1, p=0.057)$. Therefore, because cardioplegia dosage was based on the body weight, the initial dose $(20 \mathrm{ml} / \mathrm{kg}$ body weight) per gram of myocardium was slightly lower in the adult hearts ( $6.3 \pm 0.3$ versus $7.1 \pm 0.3 \mathrm{ml}$ cardioplegic solution per gram LV, $p=0.068$ ), and, therefore, delivery of cardioplegic solution per gram of myocardium was greater in the senescent hearts. These data, coupled with the lack of any detectable gross coronary artery atherosclerosis, suggest that the lack of myocardial protection in the senescent hearts is unlikely to be due to simple inadequate delivery of cardioplegic solution.

On a macroscopic level, inadequate systolic myocardial preservation in the senescent hearts could be related to the regional hypoperfusion even in the 
\% Recovery of function after cardioplegic arrest

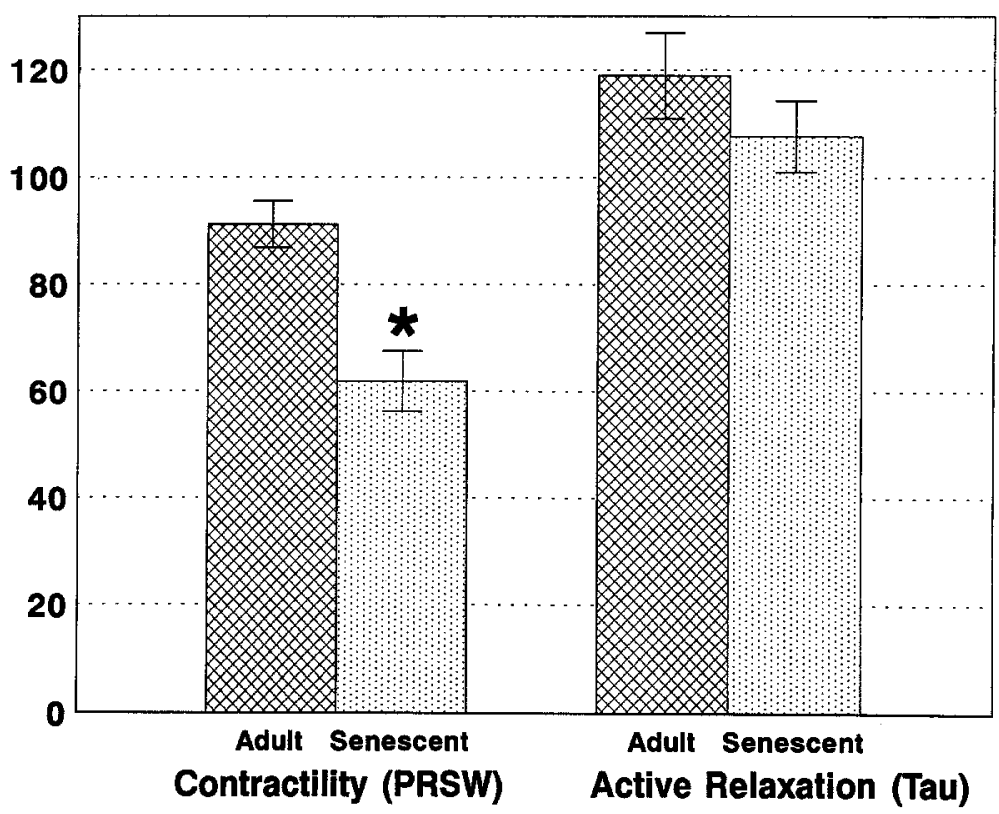

Fig. 1. Percentage recovery of contractility and active relaxation after cardioplegic arrest. Percentages expressed as postarrest value/prearrest value $\cdot 100$. Data: mean \pm standard error of the mean; ${ }^{*} p<0.025$ versus adult.

absence of atherosclerotic disease. An age-dependent decrease in maximal coronary artery blood flow per $100 \mathrm{gm}$ tissue and a decrement in the endocardial/epicardial flow ratio has been described as potentially leading to ischemic vulnerability in the endocardium. ${ }^{15}$ Furthermore, although arteriolar density in the senescent hearts is preserved when compared with adult hearts, there is an age-related decrease in the ratio of lumen diameter to wall thickness in the arterioles, suggesting a potential mechanism for the decreased coronary reserve associated with aging. ${ }^{16}$ That these morphometric changes are associated with age-dependent myocyte hypertrophy ${ }^{17}$ is postulated to lead to further ischemic vulnerability in the senescent myocardium. ${ }^{18}$

In the present study, however, it seems unlikely that the senescent intolerance to cardioplegic arrest is solely due to age-associated alterations in the microvasculature. The use of hypothermic cardioplegic arrest resulted in prompt diastolic arrest in both groups of hearts. Intramyocardial temperatures were easily maintained at about $10^{\circ} \mathrm{C}$ and myocardial oxygen consumption was similarly low in both groups at levels appropriate for adequate myocardial preservation. ${ }^{19}$ Therefore, global metabolic processes seem to have been appropriately slowed with the combination of hypothermia and hyperkalemic arrest. The potential for regional perfusion deficits leading to global dysfunction was not specifically evaluated in the present study.

Few studies have investigated the senescent response to hypothermic ischemic injury. Frolkis and coworkers $^{4}$ have described age-dependent alterations in calcium handling during low-flow ischemia. Although low-flow ischemia is not directly applicable to the present study, a greater increase in sarcolemmal calcium influx and a greater decrement in sarcoplasmic reticulum calcium uptake were noted in the senescent hearts during ischemia. The resulting increase in the intracellular calcium levels (during low-flow ischemia) suggests that the senescent myocyte has a limited ability to function under ischemic conditions. These observations support the data of Misare, Krukenkamp, and Levitsky, ${ }^{8}$ where global normothermic ischemia in a large animal model was more poorly tolerated in the senescent than in the adult sheep heart.

Despite the lack of systolic preservation in the senescent hearts, active relaxation assessed with tau was more prolonged in the adult hearts. A directionally similar, but not statistically significant prolongation was also present in the senescent hearts. The disparate effect may be related to an age-dependent decrease in the ratio of fast (V1) to slow (V3) 
Volume 109, Number 2

Table III. Contractility data: PRSW relationship parameters

\begin{tabular}{|c|c|c|c|c|c|c|}
\hline \multirow[b]{2}{*}{ Exp. No. } & \multicolumn{3}{|c|}{ Prearrest } & \multicolumn{3}{|c|}{ Postreperfusion } \\
\hline & Slope & $x$ Intercept & $r$ Value & Slope & $x$ Intercept & $r$ Value \\
\hline \multicolumn{7}{|c|}{ Adult } \\
\hline 3068 & 56.44 & 83.02 & 0.9986 & 58.12 & 92.46 & 0.9992 \\
\hline 3075 & 70.05 & 83.87 & 0.9992 & 54.02 & 80.07 & 0.9941 \\
\hline 3100 & 50.78 & 57.41 & 0.9990 & 51.45 & 72.12 & 0.9897 \\
\hline 3101 & 44.18 & 61.75 & 0.9923 & 39.13 & 82.55 & 0.9850 \\
\hline 3102 & 73.71 & 67.56 & 0.9840 & 58.44 & 91.51 & 0.9951 \\
\hline 3111 & 92.02 & 56.36 & 0.9994 & 78.28 & 52.62 & 0.9939 \\
\hline 3115 & 45.00 & 65.15 & 0.9734 & 49.92 & 92.88 & 0.9926 \\
\hline 3118 & 77.24 & 90.74 & 0.9964 & 65.00 & 80.23 & 0.9949 \\
\hline Mean & 63.68 & $70.73^{*} \dagger$ & 0.9928 & 56.80 & 80.56 & 0.9931 \\
\hline SEM & 6.09 & 4.69 & & 4.07 & 4.76 & \\
\hline \multicolumn{7}{|c|}{ Senescent } \\
\hline 3071 & 51.29 & 71.90 & 0.9773 & 29.86 & 64.42 & 0.9870 \\
\hline 3073 & 48.18 & 149.20 & 0.9943 & 30.00 & 120.04 & 0.9877 \\
\hline 3105 & 71.18 & 111.58 & 0.9929 & 36.05 & 96.39 & 0.9581 \\
\hline 3109 & 62.97 & 99.61 & 0.9946 & 43.54 & 98.11 & 0.9921 \\
\hline 3112 & 48.75 & 175.62 & 0.9857 & 18.12 & 101.20 & 0.9938 \\
\hline 3113 & 64.86 & 132.25 & 0.9916 & 53.12 & 130.00 & 0.9878 \\
\hline \multirow[t]{3}{*}{3120} & 50.44 & 111.84 & 0.9942 & 37.09 & 109.98 & 0.9939 \\
\hline & 56.81 & 121.71 & 0.9901 & $35.40 \%$ & 102.88 & 0.9858 \\
\hline & 3.52 & 12.86 & & 4.20 & 7.91 & \\
\hline
\end{tabular}

Data are mean \pm standard error of the mean.

${ }^{*} p<0.025$ versus senescent prearrest.

$p=0.09$ versus adult postreperfusion.

$\ddagger p<0.025$ versus senescent prearrest or adult postreperfusion.

Table IV. Diastolic data: Active relaxation, estimated with the time constant of isovolumic pressure decay $($ tau), and passive myocardial properties, estimated with the exponential constants ( $\alpha$ and $\beta$ ) of the enddiastolic pressure-volume relationship

\begin{tabular}{lccccccc}
\hline & \multicolumn{3}{c}{ Adult } & & \multicolumn{2}{c}{ Senescent } \\
\cline { 2 - 4 } \cline { 2 - 3 } & Tau & $\alpha$ & $\beta$ & & Tau & $\alpha$ & $\beta$ \\
\hline Pre & $42.5 \pm 3.3$ & $0.54 \pm 0.10$ & $0.028 \pm 0.009$ & & $48.8 \pm 3.5$ & $0.48 \pm 0.31$ & $0.037 \pm 0.010$ \\
Post & $49.3 \pm 3.1^{*}$ & $0.57 \pm 0.19$ & $0.028 \pm 0.002$ & & $52.3 \pm 4.5$ & $0.47 \pm 0.22$ & $0.029 \pm 0.007$ \\
\hline
\end{tabular}

Data are mean \pm standard error of the mean.

${ }^{*} p<0.05$ versus prearrest adult.

myosin isomers. ${ }^{20}$ Because alterations in the time course of isovolumic relaxation are thought to reflect myofilament properties rather than sarcoplasmic reticulum function, ${ }^{21}$ the relative tolerance of the different myosin isomers to reperfusion injury may contribute to the relatively greater prolongation of active relaxation in the adult hearts. Further investigation at the biochemical level is needed to elucidate the relative contribution of previously described age-dependent biochemical changes to the disparate pattern of tolerance to cardioplegic arrest demonstrated in the present study.

In the present study, age-related differences in the response to cardioplegic arrest are described. Spe- cifically, senescent hearts had a greater decrement in systolic function than adult hearts; conversely, adult hearts had a greater decrement in the rate of active relaxation. This differential response supports the concept that senescent hearts are not simply adult hearts in "old" bodies but are a distinctly defined subset of hearts with unique biochemical and morphologic properties. Therefore the validity of extrapolating myocardial protective strategies from adult laboratory data to the senescent patient may be inappropriate.

Evaluation of current myocardial protective strategies in light of age-dependent differences in the response to cardioplegic arrest should result in 
regimens more appropriate for the senescent patient. Equally important clinically is the need to recognize that pharmacologic support for the postbypass heart may require different interventions in an age-dependent manner (e.g., lusitropic versus inotropic agents). Better understanding of the individual biochemical defects associated with senescence is needed to allow precise pharmacologic support for the aged heart.

\section{REFERENCES}

1. Edmunds LH, Stephenson LW, Edie RN, Ratcliffe MB. Open-heart surgery in octogenarians. N Engl J Med 1988;319:131-6.

2. Horvath KA, DiSesa VJ, Peigh PS, Couper GS, Collins JJ, Cohn LH. Favorable results of coronary artery bypass grafting in patients older than 75 years. J THORAC CARdiovasC SuRg 1990;99:92-6.

3. Dobson JG, Fenton RA. Adenosine inhibition of beta-adrenergic induced responses in aged hearts. Am J Physiol 1993;265:H494-503.

4. Frolkis VV, Frolkis RA, Mkhitarian LS, Fraifeld VE. Age-dependent effects of ischemia and reperfusion on cardiac function and $\mathrm{Ca}^{++}$transport in myocardium. Gerontology 1991;37:233-9.

5. Ataka K, Chen D, Levitsky S, Jimenez E, Feinberg H. Effect of aging on intracellular $\mathrm{Ca}^{++}, \mathrm{pH}_{\mathrm{i}}$, and contractility during ischemia and reperfusion. Circulation 1992;86(Suppl):II371-6.

6. Lakatta EG, Yin FC. Myocardial aging: functional alterations and related cellular mechanisms. Am J Physiol 1982;242:H927-41.

7. Anversa P, Palack AL, Sonnenblick EH, Olivetti G, Meggs LG, Caposso JM. Myocyte cell loss and myocyte cellular hyperplasia in the hypertrophied aging rat heart. Circ Res 1990;67:871-85.

8. Misare BD, Krukenkamp IB, Levitsky S. Age-dependent sensitivity to unprotected cardiac ischemia: the senescent myocardium. J THORAC CARDIOVASC SURG 1992;103:60-5.

9. Folette DM, Fey K, Buckberg GD, et al. Reducing postischemic damage by temporary modification of reperfusate, calcium, potassium, $\mathrm{pH}$, and osmolarity. J ThORAC CARDIOVASC SURg 1981;82:221-38.

10. Teoh KH, Christakis GT, Weisel RD, et al. Acceler- ated myocardial metabolic recovery with terminal warm blood cardioplegia. J THORAC CARDIOvasC SURG 1986;91:888-95.

11. Krukenkamp IB, Silverman NA, Kollmorgen TA, Levitsky S. Preloading history influences pressurevolume derived indices of myocardial contractility in the ejecting canine left ventricle. J THORAC CARDIOVASC SURG 1989;97:551-62.

12. Glower DD, Spratt JA, Snow ND, et al. Linearity of the Frank-Starling relationship: the concept of preload recruitable stroke work. Circulation 1989;80: 1378-87.

13. Weiss JL, Frederiksen JW, Weisfeldt ML. Hemodynamic determinants of the time course of fall in canine left ventricular pressure. J Clin Invest 1976;58: 751-60.

14. Chitwood WR, Hill RC, Sink JD, Wechsler AS. Diastolic ventricular properties in patients during coronary revascularization. J THORAC CARDIOVASC SURG 1983;85:595-605.

15. Hachamovitch R, Wicker P, Capasso JM, Anversa P. Alterations of coronary blood flow and reserve with aging in Fischer 344 rats. Am J Physiol 1989;256:H6673.

16. Vitullo JC, Penn MS, Rakusan K, Wicker P. Effects of aging on coronary arteriolar density. Hypertension 1993;21:406-14.

17. Olivetti G, Melissari M, Caposso JM, Anversa P. Cardiomyopathy of the aging human heart: myocyte loss and reactive cellular hypertrophy. Circ Res 1991; 68:1560-8.

18. Anversa P, Caposso JM, Ricci R, Sonnenblick EH, Olivetti G. Morphometric analysis of coronary capillaries during physiologic myocardial growth and induced cardiac hypertrophy: a review. Int $\mathbf{J}$ Microcirc 1989;8:353-63.

19. Partington MT, Acar C, Buckberg GD, Julia P, Kofsky ER, Bugyi HI. Studies of retrograde cardioplegia. I. Capillary blood flow distribution to myocardium supplied by open and occluded arteries. J THORAC CARDIOVASC SURG 1989;97:605-12.

20. Lakatta EG. Cardiac muscle changes in senescence. Ann Rev Physiol 1987;49:519-31.

21. Brutsaert DL, Sys US. Relaxation and diastole of the heart. Physiol Rev 1989;69:1228-35. 